Paediatrica Indonesiana $14: 25-\quad 2532$ Jan. - Feb. $19 \%$.

From the Department of Child Health, Medical School,
University of Indonesia, Jakarta.

Diaphragmatic Paralysis
(Case Report)

by

S. ZULKIFLI, H.E. MONINTJA and M. SUTAN ASSIN

Unilateral paralysis of the diaphragm is a rare disease in the newborn (Schaffer and Avery, 1971).

For the first time Naunyn (1902) published a case of diaphragmatic paralysis with homolateral Erb's palsy.

Most phrenic nerve paralysis occur on the right side, and about $75 \%$ are accompanied by homolateral Erb's palsy (Schaffer and Avery, 1971). Most cases follow difficult breech deliveries. Earlier literature however stated that some cases occured in normal vertex presentation or other presentations as well (Schiffrin, 1952). Cavrot and Richard (1957) reviewed the whole literature and found 74 cases of diaphragmatic paralysis, of which 21 were isolated ones. Since then there had been no other publication, until Adams and Gyepes (1971) reported one case which had been initially regarded as a cyanotic congenital heart disease. Recently, Smith (1972) published a case of an isolated one.

To the authors knowledge not one publication on diaphragmatic paralysis in the newborn is available in the Indonesian literature. This paper communication is to report some cases of diaphragmatic paralysis with Erb's palsy in the newborn and in early infancy detected in Jakarta.

\section{Case I:}

A male Indonesian baby $\mathbf{M}$, was born on May 31, 1971, at the Obstetric Department of the Dr. Tjipto Mangunkusumo General: Hospital. $\mathrm{He}$ was the first child of a 24-year-old mother, whose pregnancy was uneventful. The baby was delivered by breech presentation with slight difficulty in delivering the shoulder and the head. The Apgar score was 4 in the first minute. Clearing the air passage and oxygen administration improved the general condition slightly. 
The baby was transferred to the neonatal ward in a lethargic condition with a negative Moro's reflex. He was dyspnoeic, cyanotic and grumting. The respiration rate was $60 / \mathrm{mi}-$ nute. The body weight was $2550 \mathrm{gm}$ and boay length was $45 \mathrm{~cm}$. Heart and lungs were normal. The treatment consisted of intravenous fluid drip with a solution of glucose $10 \%$ and sodium bicarbonate $1.5 \%$ in a four to one volume concentration. Antibiotics (combination of Penicilline and Kanamycin) and oxygen administration were given intermittently. The following day with the improvement of the motoric function, an Erb's palsy of the right hand was apparent. The thorax photo showed no abnormality (see fig. 1). At the age of 2 weeks the infant revealed a pansystolic murmur of grade III with the punctum maximum at the 3 rd and 4th intercostal space on the left sternal border which was elinically very suggestive of V.S.D. The baby was discharged in a rather good condition with increased body weight and without apparent tachypnea.

At home the baby developed a persistent tachypnea although without cyanosis and lung abnormalities or conventional clinical examination. At the age of $1 \frac{1}{2}$ months a second worax photo showed evidently a right hemidiaphragm palsy (the right hemidiaphragm was elevated $3 \frac{1}{2}$ spaces above the left and the mediastinum was shifted to the left) (see fig. 2).

\section{Case II :}

$R$, a female Indonesian baby, was born to a 30-year-ald mother on June 9,1971 , at the Obstetric Department of the Dr. Tjipto Mangunkusumo General Hospital. She was the third child and there were no abnormalities during the previous pregnancies and deliveries. In the third trimester of this last pregnancy, external version was twice attempted to correct the breech position but without success. The baby was delivered by breech extraction, with the umbilical cord around its neck. She did not ery instantly, the Apgar score was 2 in the first minute. Resuscitation by suctioning; mouth to mouth respiration, oxygen administration, glucose $40 \%$ and sodium bicarbonate $7.5 \%$ into the umbilical veiri were performed. The baby began to breath spontaneously bui irregularly after 10 minutes of artificial respiration. She was transferred to the neonatal ward still in a lethargic and weak condition, with a body weight of $3530 \mathrm{gm}$ and a body length of $50 \mathrm{~cm}$.

She was dyspnoeic, grunting and cyanotic; the respiration rate was 60/minute. Moro's reflex and other physiologic reflexes were decreased to negative. The thorax was symmetrical in form and movement, fine moist rales were detected over the base of both lungs. The thorax photo showed bronchopneumonia, the right hemidiaphragm was elevated for about 3 interspaces above the left, 


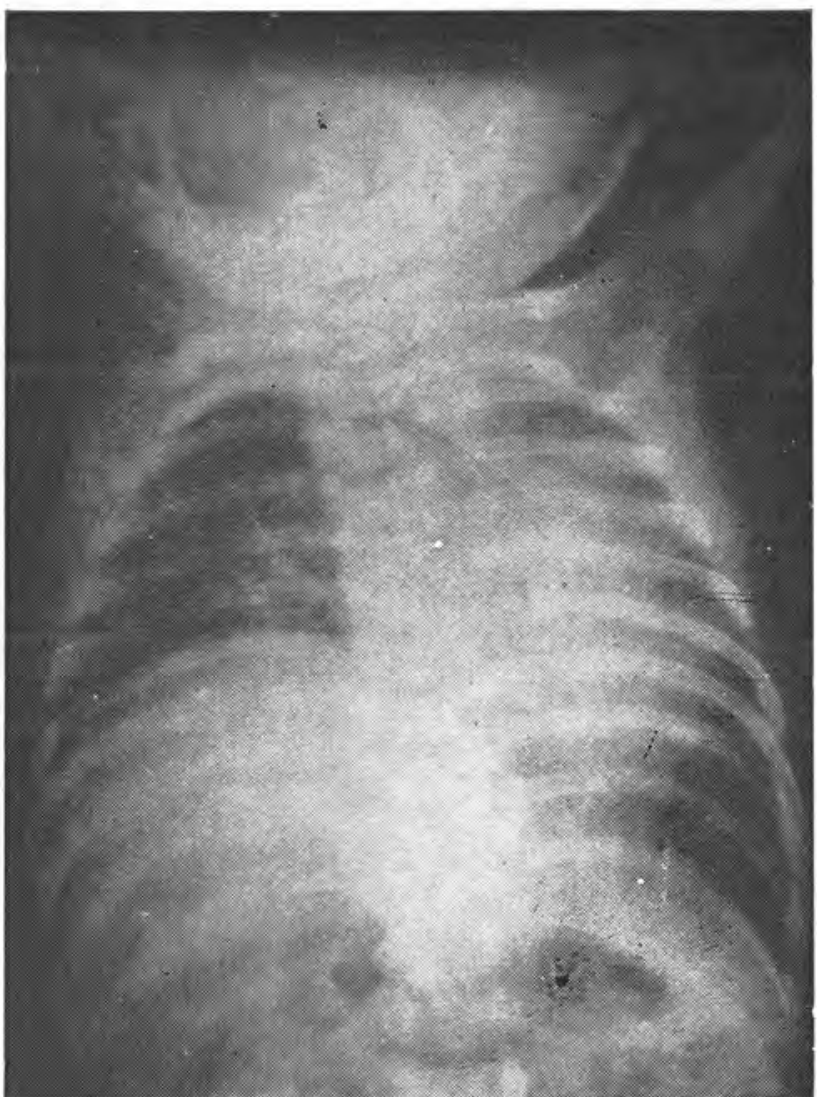

FIG. 1. Case I-Rontgenogram of the thorax showing no abnormality. 


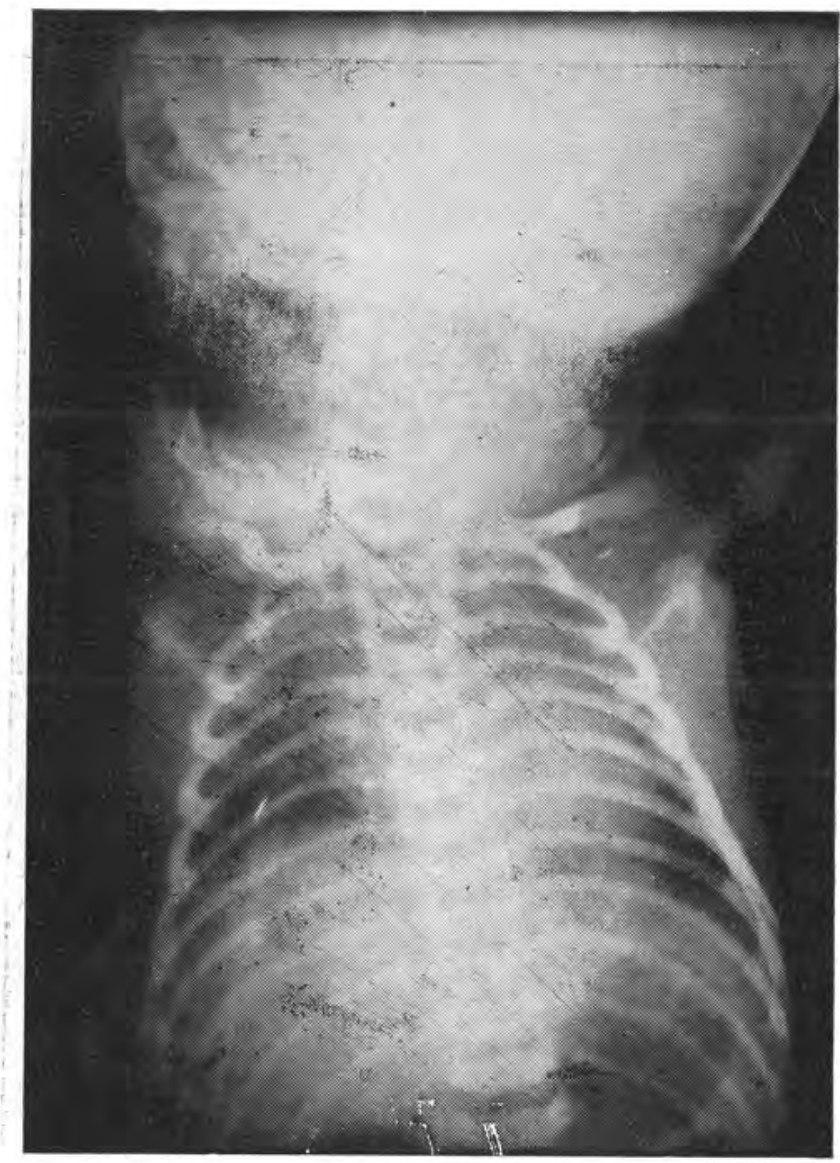

FIG. 2. Case $I$-The second rontgenogram at $1 \frac{1}{2}$ month old showing right hemidiaphragm paralysis and marked shifting of the heart to the left side. 


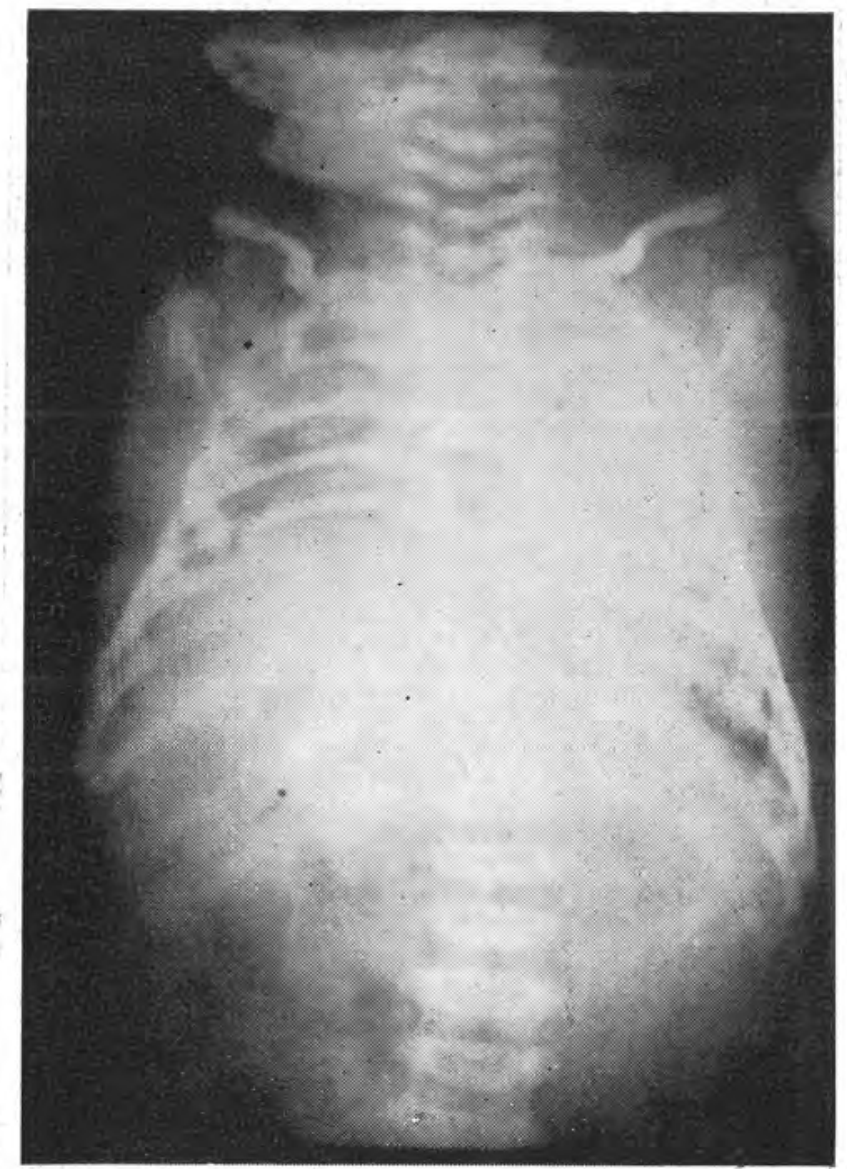

FIG. 3. Case II-Rontgenogram of the thorax showing bronchopneumonia, right hemidiaphragm paralysis and shifting of the heart to the left side. 


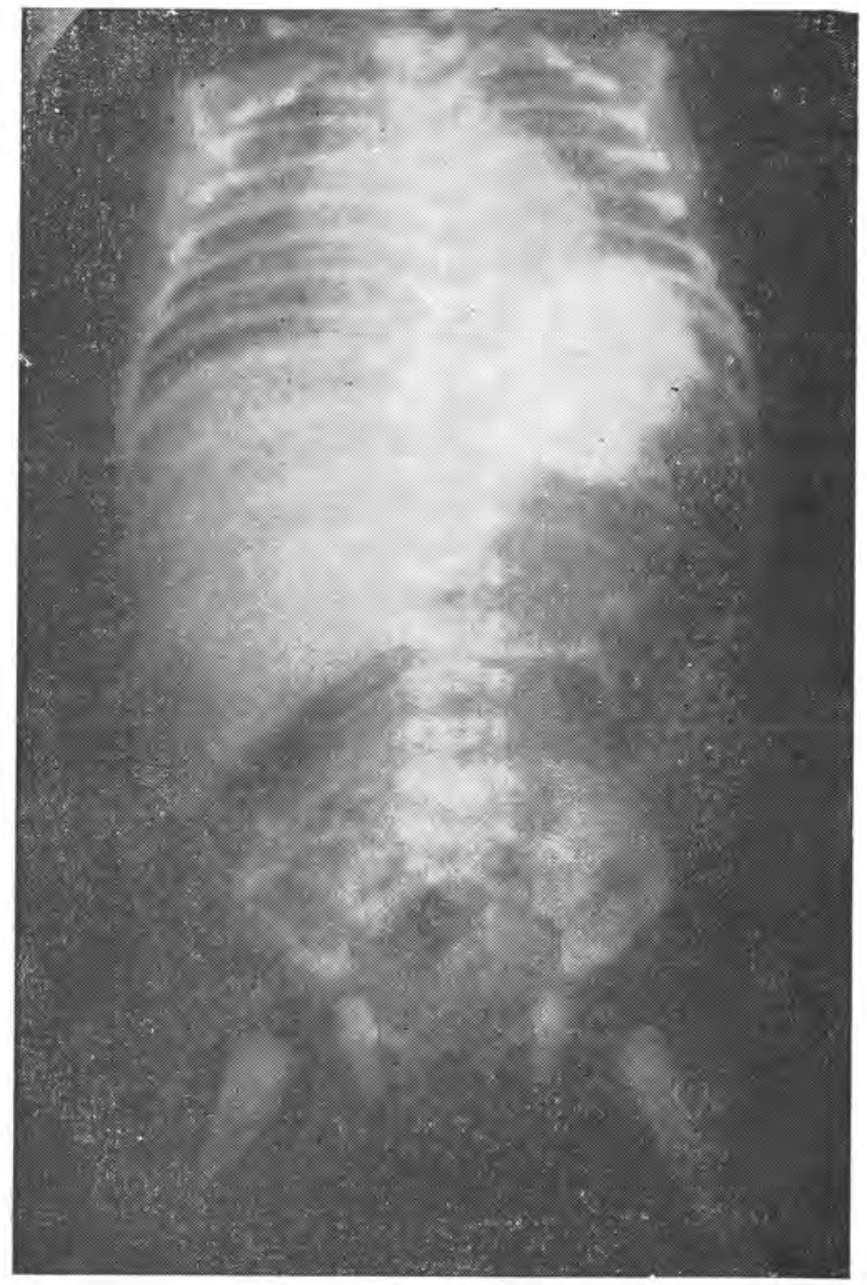

FIG. 4. Case III-Rontgenogram with Ba-contrast (orally) showing the left hemidiaphragm elevated slightly above the right side and the mediastinum was shifted to the right side. Fluoroscopical examination confirmed the diagnosis of left hemidiaphragm paralysis. 


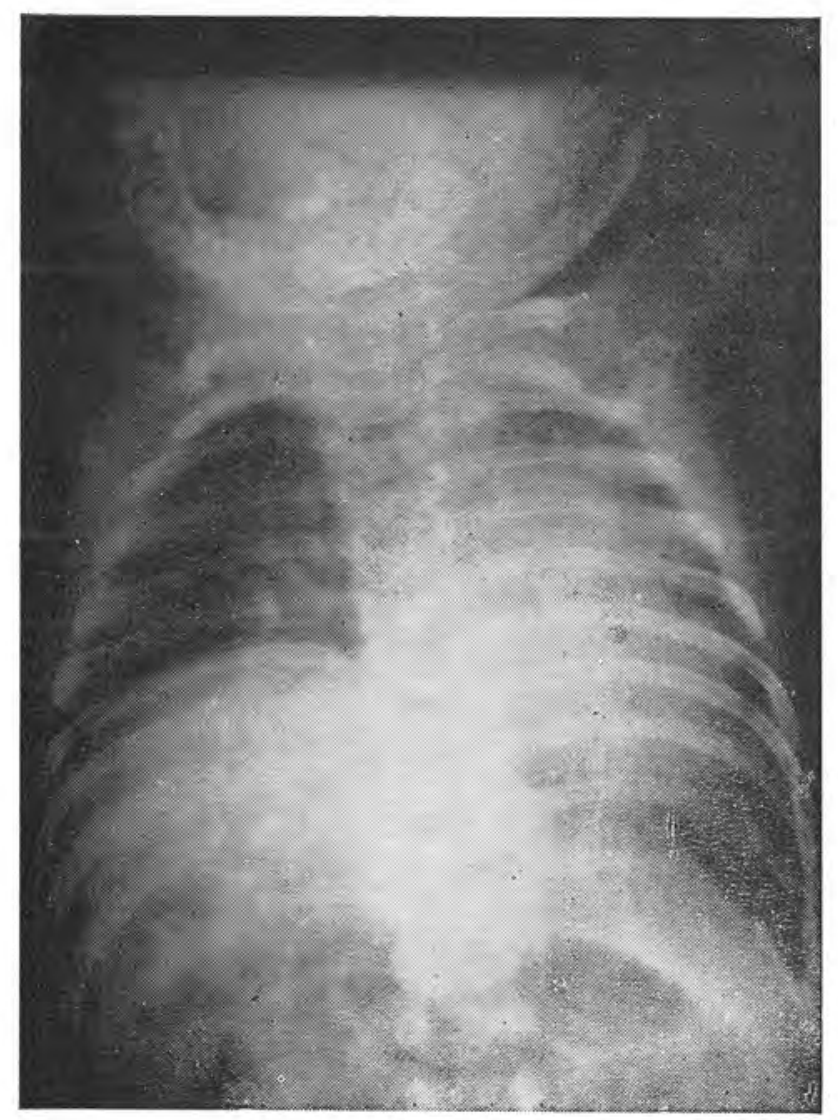

FIG. 5. Case IV-Rontgenogram of the thorax showing bronchopneumonia, right hemidiaphragm paralysis and shifting of the heart to the left side. 


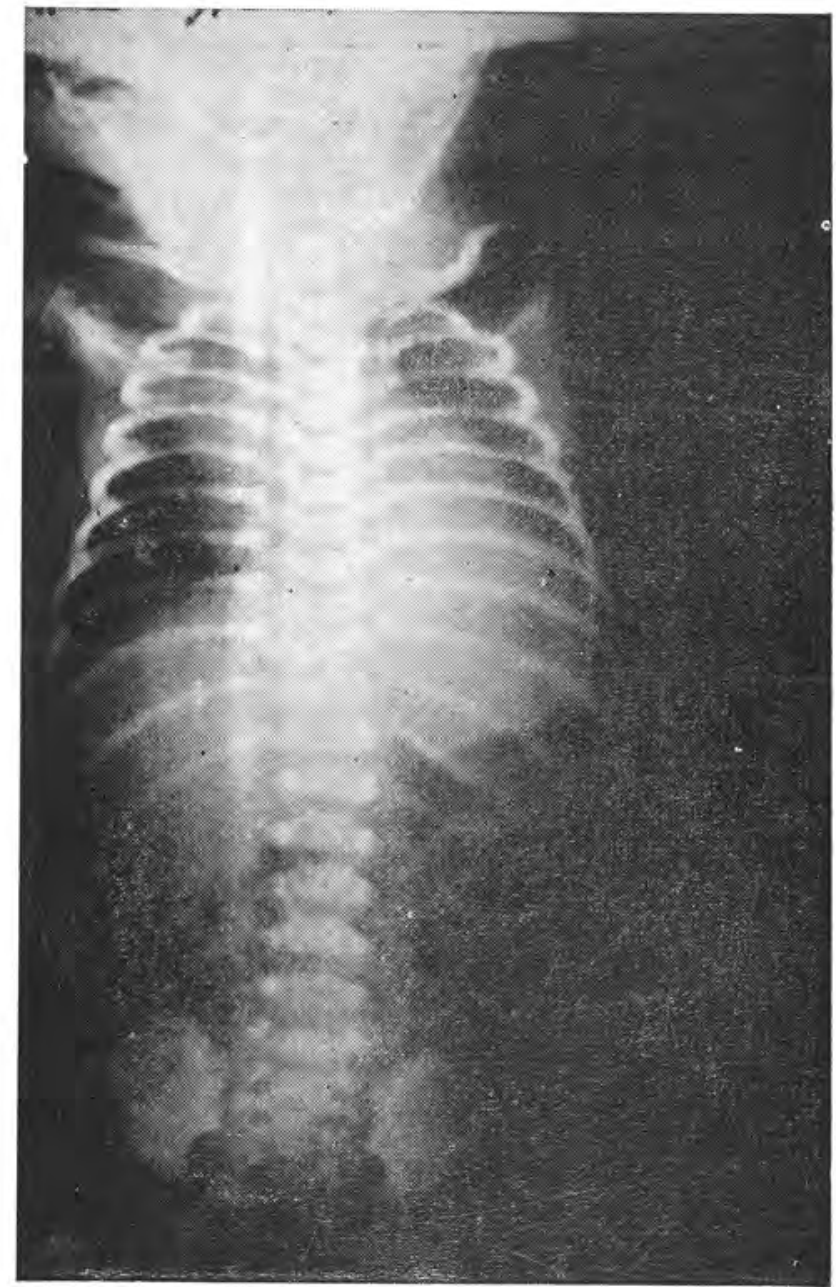

FIG. 6. Case V-The first rontgenogram of the thorax showing no abnormality except for the thymic gland enlargement. 


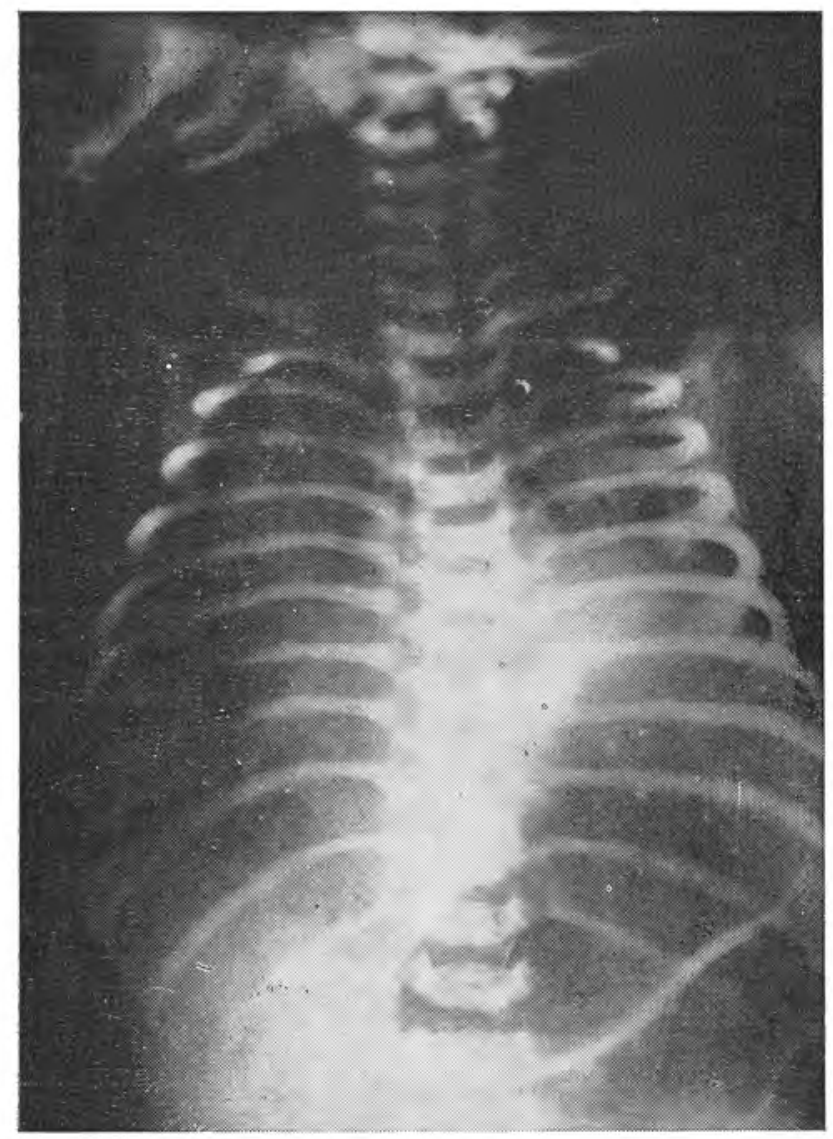

FIG. 7. Case $V$-The second rontgenogram showing the left hemidiaphragm paralysis with the heart shifted to the right side. Further fluorosocpidal examination confirmed the diagnosis. 
and the mediastinum seemed to be shifted to the left (see fig. 3). Intravenous fluid drip by an indwelling umbilical catheter of a solution containing glucose $10 \%$ and sodium bicarbonate $1.5 \%$ was given, besides antibioties (Penicilline and Kanamycin) and oxygen intermittently. Examination at the following days revealed Erb's palsy of the right arm. Unfortunately the condition became worse, and the infant died on the second day.

\section{Case III :}

$\mathrm{P}$, a female Indonesian baby, was born on July 20,1971 , to a 35-yearold mother at the Obstetric Department of the Dr. Tjipto Mangunkusumo General Hospital. She was the seventh child of a healthy mother. Pregnancy was uneventful. The delivery was at the beginning attended by an indigenous midwife at home. Because of the shoulder presentation with the left arm prolapsing the mother was sent to the hospital. A Caesarian Section was immediately performed under ketalar and ether anaesthesia. The Apgar score was two in the first minute and six in the fifth minute. Mouth to mouth respiration, oxygen and intravenous glucose $40 \%$ and sodium bicarbonate $7.5 \%$ were given. The baby was lethargic, dyspnoeic and cyanotic. The Moro reflex was negative. The body weight was 2950 gm, the body length $50 \mathrm{~cm}$. The thorax was asymmetrical with a hematoma and edema in the left upper hemitho- rax and during inspiration this part moved more than the right hemithorax. Fine moist rales were heard over the base of both lungs. The thorax photo revealed infiltrates suggestive of bronchopneumonia, without apparent abnormality of the diaphragm. Intravenous drip, antibiotics, oxygen and special nursing care were given. On the following days examination revealed the presence of a right hand palsy and persisting tachypnea without apparent cyanosis.

At the age of 4 days, the thorax photo was repeated with $\mathrm{Ba}$ orally and showed the left hemidiaphragm elevated slightly above the right and the mediastinum shifted slightly to the right (see fig. 4). On fluoroscopy a paradoxal movement of the left hemidiaphragm was obvious, so the presence of a phrenic nerve injury was confirmed. On the 9th day the baby was discharged by request of the parents; the tachypnea disappeared and the baby thrived well.

\section{Case IV :}

$\mathrm{H}$, a male Indonesian infant of $2 \frac{1}{2}$ months old, was admitted to the Department of Child Health, Dr. Tjipto Mangunkusumo General Hospital on August 14, 1972. He was born to a 24-year-old mother at a maternity hospital with a breech presentation. The birth weight was $3550 \mathrm{gm}$, the body length was $49 \mathrm{~cm}$ and mild asphyxia neonatorum was present. Erb's palsy of the right arm and a slight tachypnea persisted when the 
boy was discharged from the maternity hospital. Three days prior to admission, the boy became more dyspnoeic following a cough and a slight fever. The physical examination on admission revealed marked ajyspnea (respiration rate was 68/minute) and marked Erb's palsy of the right hand. The right hemithorax was more flat and moved less than the left part. There was dullness with fine moist rales over the base of both lungs. The thorax photo confirmed the diagnosis of bronchopneumonia. The right hemidiaphragm was elevated about $3 \frac{1}{2}$ interspaces above the left, and the heart was shifted to the left (see fig. 5). By conservative treatment and antibiotics the tachypnea disappeared and by physiotherapy the arm palsy improved. The boy was discharged afiter two weeks of hospitalization.

\section{Case $V$ :}

$\mathrm{N}$, a female Indonesian neonate was born on February 11, 1973, in the Obstetric Department of the Dr. Tjipto Mangunkusumo General Hospital. She was the first child of a 17year-old mother with an uneventful pregnancy. The baby was delivered by forcipal extraction on the indication of toxemia parturientum, premature rupture of the membrane and persistent occiput posterior position of the head. She was asphyxiated, the Apgar score was 2 in the first minute and 4 in the fifth minute. Intermittent positive pressure ventila- tion by endotracheal intubation was given, besides $10 \mathrm{ml}$ sodium bicarbonate $7.5 \%$ and $4 \mathrm{ml}$ glucose $40 \%$ intravenously into the umbilical vein.

In the neonatal ward the baby remained weak with decreased Moro's and other physiologic reflexes. The body weight was $3220 \mathrm{gm}$, the body length $48 \mathrm{~cm}$ and a large caput succedaneum was present on the head. She seemed to be dyspnoeic, slightly cyanotic with a respiration rate of 60 times per minute, but grunting and retraction were not detected. The photo of the thorax revealed normal lungs and heart, and an enlargement of the thymic gland (see fig. 6). She was treated with antibiotics (Procaine Penicilline and Kanamycin), intravenous fluid drip of glucose $5 \%$ and sodium bicarbonate $1.5 \%$ in a four to one volume solution and oxygen.

The next day she developed a seizure of 5 minutes duration without fever. The cerebrospinal fluid and blood sugar content were within normal limits. The neonatal fit was treated successfully with valium and dilantin. On the fifth day, with the improvement of motoric function, a left Erb's palsy was clearly seen accompanied by ptosis and miosis of the left eye. The X-Ray of the head and neck revealed no abnormality. On the 10th day of hospitalization she contracted bronchopneumonia and an acute infection of the middle ear; proper antibiotics were given 
adequately. After olinical improvement of the bronchopneumonia the tachypnea still persisted and a second thorax photo was made. The left hemidiaphragm was markedly more elevated than the right and the heart was shifted to the right side of the chest (see fig. 7). The fluoroscopic examination showed a paradoxal movement of the left hemidiaphragm and confirmed the diagnosis of phrenic nerve paralysis.

The general condition improved gradually, the dyspnea disappeared, except for the persisting slight paresis of the left arm and the left eye. The baby was discharged at the age of 4 weeks. Physiotherapy was continued ambulatorily.

\section{Discussion}

Phrenic nerve paralysis in an infant is usually present in the first 24 hours of life. Most babies show lethargy and respiratory difficulties at birth. This poor respiratory condition may be due primarily to the difficult delivery rather than to the phrenic nerve paralysis itself. The respiratory distress varies from a slight tachypnea to a severe respiratory distress syndrome which may even terminate in death. The affected hemithorax gives mostly a decreased movement, but sometimes it shows flaring during inspiration which may be due to the pronounced effect of intercostal mus- cles contraction with diminished diaphragmatic contraction. The tachypnea usually persists without any distinct abnormal finding. After several days or weeks the symptoms may disappear gradually, but may also increase in severity. The latter may be due to the needs of more expanding lung capacity for the increasing necessity of oxygen consumption of the growing infant. This phrenic nerve paralysis may resemble any of the other causes of respiratory distress such as diaphragmatic hernia, bronchopneumonia, atelectasis, massive aspiration syndrome, hyaline membrane disease, congenital heart disease and cerebral injury.

Adams and Gyepes (1971) reported a case of respiratory distress which was diagnosed initially as a eyanotic congenital heart disease; however heart catheterisation excluded the heart disease, and the thorax photo as confirmed by the fluoroscopic examination revealed the diagnosis of phrenic nerve palsy. It is also interesting to note that in their case the right phrenic nerve paralysis was accompanied by the left Erb's palsy.

This contralateral combination has not been reported yet before. The thorax photo can help to diagnose phrenic nerve paralysis if there is a marked elevation of one of the diaphragms (usually the right side), and often with obvious shifting of the mediastinum to the unaffected side. Normally, in the first six 
months of life, the left hemidiaphragm is slightly higher than the right one, and in the second half year the two hemidiaphragms are usually on the same level; after the first year of life the right hemidiaphragm is always higher than the left (Caffey, 1970). But of course there are some exceptional cases. If the hemidiaphragm is elevated abnormally, especially if associated with brachial palsy, then the diagnosis of phrenic nerve paralysis is justified even if only based on the thorax photo. But sometimes the elevation of the diaphragm is not quite so obvious, so that the diagnosis can only be confirmed by fluoroscopic examination. We may see the see-saw or paradoxal movement of the affected hemidiaphragm; it moves upwardly instead of downwardly during inspiration despite normal movement of the unaffected hemidiaphragm.

In our cases, 3 out of 5 cases ( $\mathrm{Ca}$ se I, II, IV) were delivered in breech presentation with some degree of difficulty in shoulder or head delivery; but all of them were associated with right Erb's palsy. The other 2 cases, one case (Case III) was in transverse (shoulder) presentation and the other one (Case III) was in the vertex presentation. In the 3rd case, an operation was done because of a shoulder presentation with prolapse of the arm; this case had a contralateral paralysis of the right brachial nerve. This may be due to the hyperextension of the left phrenic nerve by the prolapse of the left arm, and the pulling out the right arm during surgical delivery of the body. The 5 th case was delivered by forcipal extraction, with the complication of left phrenic nerve paralysis, homolateral Erb's pallsy and Horner's syndrome.

So 3 cases (Case I, II, IV) had homolateral paralysis of the right side, one case (Case V) had homolateral paralysis of the left side, and one case (Case III) had contralateral paralysis of right brachial and left phrenic nerve. Adams and Gyepes (1971) reported a similar case of such a contralateral paralysis.

Two ilases of breech position (Case I, II), one case (Case III) of transverse presentation and one case (Case V) of persistent occiput position were delivered in the Obstetric Department of the Dr. Tjipto Mangunkusumo General Hospital, the other case (Case IV, breech presentation) came from a maternity hospital. In 1971 there were 3236 deliveries at the Obstetric Department, among which 275 cases $(8.25 \%)$ were breech deliveries and 122 cases $(3.13 \%)$ were in the transverse presentation; the datas of 1973 are not available yet. No cases of phrenic nerve paralysis occurred in 1972.

In all 5 cases, asphyxia neonatorum was encountered. However, resuscitation had saved their lives. Suction of the mucus in the airway passage, correction of the acidosis and caloric supply besides oxygen admi- 
nistration and good nursing were very helpful.

Four cases had bronchopneumonia as a complication, and one of them died on the second day of life; this complication and the severe asphyxia might be more important as the cause of death rather than the phrenic nerve paralysis itself. Horner's syndrome and neonatal fit as a complication occurred in the 5th case, due to traumatic injury and asphyxia.

The diagnosis of diaphragm paralysis was made on the first day (Case II), 4th day (Case III), 3rd week (Case V), at $1 \frac{1}{2}$ month (Case I) and $2 \frac{1}{2}$ month (Case IV) of life.

Fluoroscopy was only needed in $\mathrm{Ca}$ se III and Case V to confirm the diag.. nosis of left diaphragmatic paralysis. In the other cases the marked elevation of the right diaphragm associated with a homolateral Erb's palsy and clinical signs and symptoms were sufficient to make the diagnosis without the aid of fluoroscopy. The presence of marked shifting of the heart to the unaffected side on the thorax photo was detected on 4 cases (Case I, II, III, V).
There is no specific treatment of diaphragmatic paralysis, only supportive and symptomatic. Surgical intervention has not jet proved to be satisfactory. The prognosis depends on the severity of the nerve injury (only overstretching or complete avuision) and on the associated complication.

Unfortunately all of the remaining cases that survived did not come back for a further follow up examination and evaluation.

\section{Summary}

Five cases of diaphragmatic paralysis with Erb's palsy in infancy at the Child Health Department, Dr. Tjipto Mangunkusumo General Hospital, Jakarta, have been reported, possibly for the first time in the Indonesian medical literature.

A routine fluoroscopic examination on every case of respiratory distress in infancy might reveal more cases.

\section{Acknowledgement}

We greatly appreciate the help of the Radiology Subdivision of the Department of Child Health for performing the photos and fluoroscopy.

\section{REFERENCES}

1. ADAMS, F.H., and GYMPES, M.T. : Diaphragmatic paralysis in the newborn infant simulating cyanotic heart đisease. J. Pediat. 78 : 119 (1971).
2. CAFFAY, J. : Pediatric X-Ray diagnosis. 5th ed. (Jb. med. Publ., Chicago, 1970).

3. CAVROT, E., and RICHARD, J. : Paralysie diaphragmatique d'origine 
obstetricale. Brux. med., 3 : 1366 (1957) as cited from Smith (1972).

4. NAUNYN, B. : Ein Falle von Erb'scher Plexuslähmung mit gleichseitiger Sympathicuslähmung. Dtsch. med. Wschr., 28 : $52 \times(1902)$ as cited from Schifrin (1952).

5. SCHAFFER, A.J. and AVERY, M.E. : Diseases of the newborn, 3rd ed. (Saunders, Philadelphia, 1971).
6. SCHIFRIN, N.: Unilateral paralysis of the diaphragm in the newborn infant due to phrenic nerve injury, with and without associated brachial palsy. Pediatrics : 69 (1952).

7. SMITH, B.T. : Isolated phrenic nerve palsy in newborn. Pediatrics $49: 3$ (1972).

\section{zuchome}

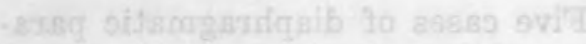

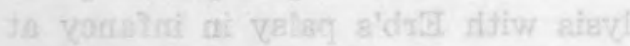

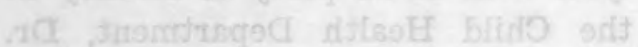

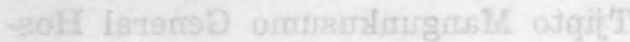
Wotroger nesd svart, patrezlst, letig

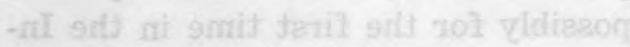
erustereftil fisoibera msiagnob

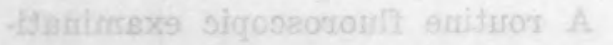

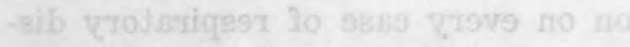

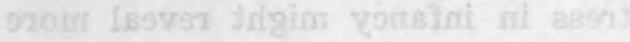

\section{Jiromgabsturomin A.}

to gied sdf efsiogrggs vifserg elW

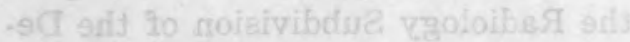
- Tolred rol nitliseff blino to Jnemtyeg vgoseorotslt brta botorig gilt gram

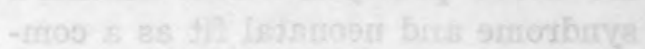
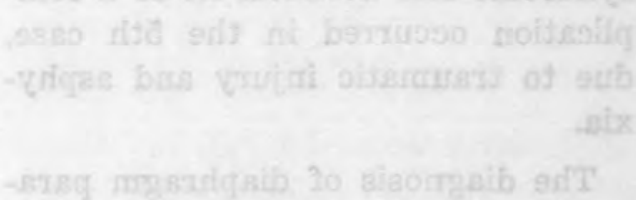

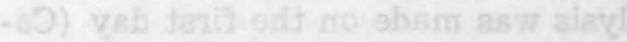

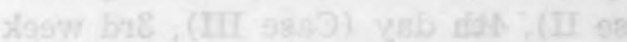

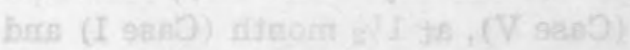

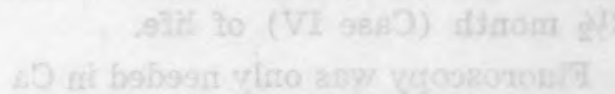

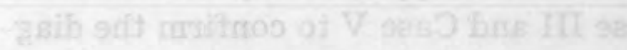

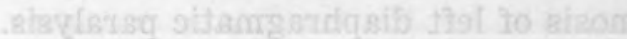

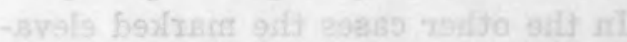

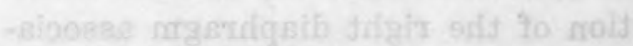

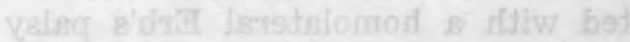
gapor amotcrutca bres angie Leoicilo bno

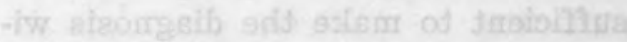

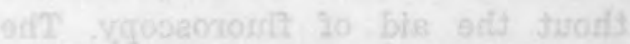

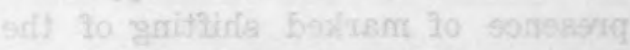

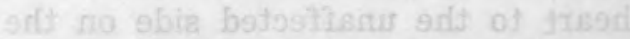

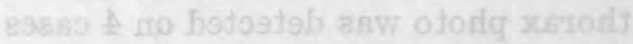
( (V III II , it ses?)

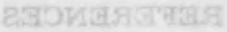

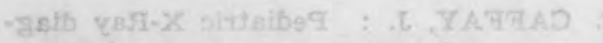

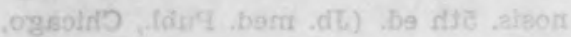

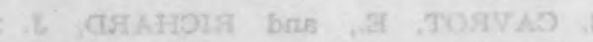

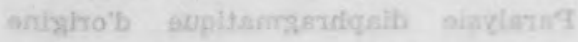

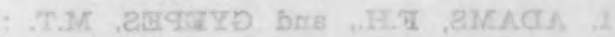

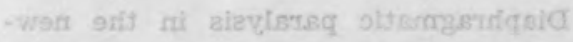

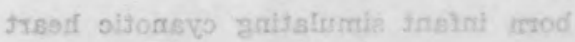

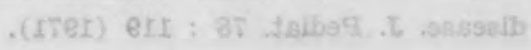

